\title{
The Effects of Translation Shifts on The Readability in Translation of Children's Literature
}

\author{
Seyyed Mohammad Hossein Ghoreishi ${ }^{1} \&$ Sirwan Aminzadeh $^{2}$ \\ ${ }^{1}$ Department of Linguistics, Humanities Faculty, University of Birjand, Birjand, Iran \\ ${ }^{2}$ Department of Translation studies, foreign languages Faculty, ATU University, Tehran, Iran \\ Correspondence: Seyyed Mohammad Hossein Ghoreishi, Department of Linguistics, Humanities Faculty, \\ University of Birjand, Birjand, Iran.
}

Received: March 6, 2016 Accepted: April 20, 2016 Online Published: May 20, 2016

doi:10.5539/ass.v12n6p239 URL: http://dx.doi.org/10.5539/ass.v12n6p239

\begin{abstract}
This study examines the effects of translation shifts on the level of readability in translating children's literature. It conducts this study on three Persian translations of "Alice's Adventures in the Wonderland" to rank Catford's shifts based on their effects on the readability of translation. To do that, in this study, the typology of Catford's shifts will be extended, and the way to measure text readability will be modulated to include the effects of these shifts on the translation readability.

Thus, Ranking 14 types of shifts, the study reveals that complex shifts (represented as clauses and groups in the texts) are more effective than simple shifts (which are symbolized as single word -nouns and adjective, determiners- in the text) on the readability of translations. This means the complex shifts are more recognizable for children. Of course, verbs, although are mostly the representatives of simple shifts, are very effective on readability of text. Since, they, along with clause and group segments, are will recognizable for them. Therefore children cannot determine the place of single words in the text, but are expert in realizing word clusters in form of clauses and groups.
\end{abstract}

Keywords: children's literature, translating children's literature, Catford's shifts, readability

\section{Introduction}

Linguistic study of translation, although is very controversial, is one the most fruitful activity which aims to analyze and evaluate translations to propose some useful and advanced translation strategies, methods, and procedures to face translation problems in the text. Here we do not claim that Translation studies are a sub branch of the science of Linguistics. We accept Translation studies as an independent field of study with its different issues and concerns than those of Linguistics.

At the other hand, applied Linguistics is a special field in which any kind of knowledge (e.g. linguistics, sociology, psychology, etc) could be used to solve the intended problem (here translational problem). To clarify the issue we refer to Joseph L. Malone (1988) in his book on "The Science of Linguistics in The Art of Translation" uses pure-linguistic science of theoretical linguistics in the service of the applied linguistics enterprise of translation. He encourages others to carry forth and improve the exploitation of the open-ended resources of pure-linguistics science for the fashioning of techniques and procedures to serve as applied linguistics accessories in the analysis and practice of translation.

The vital distinction between applied linguistics and pure-linguistics science in the study of translation lead us to differentiate applied linguistics from linguistics applied. Malone, respecting to this matter, states:

"The crucial point in my study is the significant degree of independence between pure linguistics and applied linguistics: not every discovery and formulation of the theoretician will be of equal value for translational purpose" (Malone, 1988, p. 2).

In other words, not every theories and findings of linguistics could be applied for studying translation, but those whose applications in real world translation have been proved should involve in the study of translation.

In this study problem to be coped with is to show the relation of readability of translation equivalence to the translation shifts in the translations of children's literature. This is linguistic-based, working on some real world 
translations. Here we are not to insert or justify some theoretical linguistics in the process of translation, but to reveal some existed relations between two linguistic variables of translation shifts and readability in the act of translation.

The nobility of new world and language for children, as new comers to the world, is much more critical than for the adults. This is because of Children's peculiarities. Presenting the new worlds for children via literature and its translation demands particular attention. In plain words, Children's literature $(\mathrm{ChL})$ and translating children's literature $(\mathrm{TChL})$ demand some specialized researches in order to cope with the problems challenging the enterprises of writing and translating for children.

In Ritta Oittinen's book entitled "Translating for Children" (2000) ChL includes all of those written (and oral) works prepared especially for children. And, at the other hand, TChL means translating works especially for children. By focusing on "especially for" we mean that the (translated) text presented to the children should be appropriate to them linguistically and psychologically, sociologically. That is, a work intended to children should contain some particular features in order to be qualified as children's work.

One of the most primitive and demanding features of both $\mathrm{ChL}$ and TChL is the text difficulty. Based on Tajvidi's article (2005) Text difficulty has two general aspects. The first one is linked to the language difficulty (readability) of the text, which is measured by readability formula. It is the extent of the lexical and structural complexities of the text (2005: 30). The second feature of text difficulty is related to the ability of the readers to understand the text (ibid). Studying the extent to which the readers' background knowledge, interest, age, gender, etc impact the text difficulty is an extra textual study (involving non linguistic issues), focusing on readership.

The next point which should be made clear is to note the importance of readability feature to the translation equivalence in TChL. We believe that the most brilliant quality of translation equivalence which should be provided in TChL is its readability. One may ask "but where are the places of equivalence adequacy and acceptability of translation equivalence to children? (two concepts of Toury's theory of translation equivalence1995)".In replying, we state that readability is prioritized over both concepts of adequacy and acceptability. Because, at the one hand, a translation equivalence whether adequate (transmitting ST content and function correctly) or acceptable (for the TT readers) must be readable for the reader. Otherwise none of these two extreme will be gained. Thus we claim that readability is the precondition of both two previous concepts, and should be observed in translation equivalence in any way.

Thus, we perform this study on three Persian translations of "Alice's Adventure in the Wonderland". We, first, compare these translations with each other to determine the most (and the least) readable translation, then, prioritize the translation shifts based on their effects on text readability in each of them, and at last, state some generalizations regarding the effectiveness of shifts on the readability in TChL.

Study on TChL is, yet, on its start point in the world and in Iran. According to Knowes And Malmkjare (1996: ix) "there is a curious discrepancy between the ubiquity and perceived importance of children's literature, and scholarly research in this field" (cited in Lathey, 2006, p. 15). That is, although children's works (and their translations) could be found in anywhere, scientific study on their qualities, as another matter, needs more serious attention. Thus, besides noticing the importance of reading materials of children by their parents and teachers or themselves, scientific analysis of the existed children's (translated) works is critically essential for improvement of this field of study.

Puurtinen believes $\mathrm{ChL}$ has two major purposes: 1- it is not only read for entertainment, recreation and literary experience; but also 2- it is used as a tool for education and socialization of children (Puurtinen, 1995: 17. cited in O' Connell, 2006, p. 19).

Despite such critical necessities of $\mathrm{ChL}$, as Zohar mentions, is a peripheral literature in the literary polysystem (1997: 25). According to O'Connell this may because books for young readers are written for the minority of children. "This literature, like women's literature, is treated in many cultural systems as peripheral and not really central to the concerns of the culture" (2006, p. 18).

Via translation, children will be exposed to the knowledge of a foreign believes and culture which could provide them with many more opportunities in life. So familiarizing children with new worlds and training them to be open minded toward them, certainly lead to enhancement of our society knowledge, power, and dignity.

This research is to determine the most readable translation of 'Alice's Adventures in the Wonderland' into Persian. This is a case study on translation shifts existed in three Persian translations of Alice in order to determine the effects of structural and lexical changes of translation equivalence (or translation shifts) on the level of readability in each of these translations. Therefore, the authors will answer the following questions: 
1. What differences do these translations have, regarding to their translation shifts?

2. The level of readability of what translation is high and what is low? Prioritize them.

3. How the shifts occurred in each translation does affect the level of readability of that translation?

4. What type of shift is the most and what is the least efficient in making the translation readable? Prioritize them.

Regarding to these questions we have some claims which are introduced in form of descriptive hypotheses. Descriptive hypotheses usually generalize statements in form of tendency. That is why we implement the verb of "tend to" in our hypotheses' statements.

1. Three Persian translations of Alice are different from each other by typology and frequency of shifts existed in each one.

2. The level of readability of these translations tends to be different from each other due to the structures and lexis contained in them.

3. The level of readability of each translation is the outcome of its shifts' impact on it.

4. The more structurally and lexically simple a shift, the more effective it tends to be on the readability of translation.

Before getting the answering of the research questions and accepting/ or rejecting these hypotheses, we should probe some theoretical backgrounds of TChL in order to:1- get some methodological advantages of them, if possible, 2- show the importance of our study as a vacuum in the domain of Translation Studies.

\section{Theoretical Backgrounds of TchL}

The involvement of Translation Studies in TChL is very weak. In 1982 Katharina Reiss noticed:

"For centuries critics have been concerned with both the theory and the practice of the complicated and complex phenomenon of translation, but scarcely anything has been said about the translation of books for children and young people" (Reiss, 1982: 7. Cited in O'Sullivan, 2005: 66).

Eithne O'Connell expressed the same surprise some years later, stating "within Translation Studies this area $(\mathrm{TChL})$ remains largely ignored by theories, publishers, and academic institutions" (O'Connell, 1999: 208.cited in Lathey, 2006:1). Nevertheless some paucity studies presented which link TChL to theoretical bases of TS. O'Sullivan summarized these studies as follows:

"The range of theoretical issues and corpora examined has expanded further to include such diverse areas as readability (cf. Puurtinen 1994), tense and translation (cf. Lathey, 2003), ideological factors (cf. Thomson Wohlgemuth, 2003) and censorship in translation (cf. Craig 2001), the interaction of image and text in the translation of picture books (cf. O'Sullivan, 1999 and Oittinen, 2003), or how the stratification into sub-genres of differential status is linked to translating practice (Desmet, 2002)" (O'Sullivan, 2005, $67)$.

We introduce some accessible studies mentioned above. According to Lathey these studies in the west have developed over the last 30 years (2006: 1). These studies (e.g. Shavit, 1986; Klingberg, 1986; Puurttinen, 1994; Oittinen, 1988/2000) are more cultural bound studies which investigate TChL internationally to see how factors like ideology, norms and (in) visibility of translators affect the transference of a children's work from source language culture to the target language culture, and what strategies to face socio cultural limitations should be applied.

Zohar Shavit (1986) considers ChL from the point of its peripheral position in the literary polysystem. This position enables the translator to manipulate the text as long as the (ideological) educational purposes are observed. In plain words, she connects his statement to the theory of polysystem of Ivan Zohar (1972).She believes that TChL has been ignored by decades, and viewed as peripheral literature. She offers an explanation for the lack of attention paid to the translation of children's books. She explains the manipulation of the original children's texts observing two principles of (1) adjustment of the text to make it appropriate and useful to the children with what society regards as educationally good for the children, and (2) adjustment of characterization and language to the children's ability to read and comprehend(2006, 26). She states that for decades the first principle was dominant, but nowadays the emphasis differs; that is, the second principle is more dominant (ibid). Thus she drives the following conclusion in five translational norms for $\mathrm{TChL}$ as follows:

1. The (translated) text must fit a model in target children's literature (for example a simple fantasy story) 
2. Some complex parts of text could be deleted. Since children are not able to understand.

3. The thematic and main structures must not be too complex.

4. Some time the source text may be changed completely in order to adapt it to the prevalent ideology.

5. The stylistic features of the text will be affected by the stylistic norms of target culture (ibid: 59).

Ritta Oittinen in his famous book entitled "Translating for Children" (2000) selects a functional approach to TCHL. She examines the interplay between translator and child readers. He begins by investigating how children think and respond to what they read. She believes that there is difference between translating for children's literature and translation of children's literature, preferring the former. That is, we should consider and meet the children's needs not, just translate as adult translator but to turn to our internal child and behave( translate in child language).

The other more active scholar at TChL is Etmer O'Sullivan (1993). She, like Oittinen, believes that the implied reader of translation of $\mathrm{ChL}$ is different from that of source text. Then she proposes a model of narrative communication composed of the implied reader of target culture and the translator. In this model the translator is the agent mediating cultural difference, often in an idiosyncratic manner rather than the invisible and voiceless instrument of cultural exchange (2006: 66).

As can be seen all of these theoretical studies have been done on the base of cultural studies. The only case study which could be found to somehow related to and similar to our study (linguistic analysis of the case) is that of Tina Puurtinen (1994). She, measuring readability of the works via cloze test, adopt an empirical and linguistic approach to her study of two translations of "The wizard of Oz" into Finnish. She sets out a methodology that rejects socio cultural issues as irrelevant to two translations that differ primarily in stylistic feature, syntax, grammar and readability. Nonetheless she evaluates a range of theoretical perspectives (including those of klingberg's and Shavit's). Her aims of measuring readability of these two versions is to judge about their acceptability (a term borrowed from Toury, 1994) to children. Since she believes that the more readable the text, the more acceptable it would be (Lathey, 2006, pp. 54-64).

By contrast we believe that being a translation readable is not always meant that the translation is acceptable as well, In other word, one translated text may be readable for the children, but it's perceived content can't be accepted by them, since they are not conform to the accepted axioms of the target culture. Nevertheless, readability is one of the preconditions of text acceptability, because it should be read and understood, and, then, be judged on its acceptance or rejection by the readers. Thus acceptability of translation is other matter related to socio cultural issue of translation. At the other hand, the common feature of our study with that of Puurtinen is the applying cloze test as a measurement of readability.

Study on TChL in Iran is a new established field of study. This topic has only been studied by M.H.Ghorashi through his dissertation (2009). He looked on the equivalence components (e.g. lexicon, structure, texture, etc) in TChL. Considering from a linguistics angle, he Analyzed translation equivalence based on semiotics.

$\mathrm{He}$, after accounting the components of translation equivalence and the dimensions of children readership, embarked on clarifying the difficulties of TChL from a semiotics point of view. he believes that textual equivalence is equals to aggregation of all equivalence components and reader's competence of reading (2009, $5)$.

Here we are analyzing translation equivalence linguistically as well, but our criterion is not considering readership sociologically and psychologically and not scrutinizing translation equivalence semiotically, but probe the readability of equivalence resulted from translation shifts. That is, the more readable the equivalence, the more catchable for children (but may not be acceptable or adequate).

Here, after reviewing the most important theories in TChL, and showing the 'state of art' -gaps and needs- in this field in the world and in Iran, we narrow our attention down on our cases of study. Thus, in the chapter three, methodology and procedures of what should be conducted in the continuum of the research will be introduced.

\section{Methodology \& Procedures}

This study is a combination of theoretical and empirical research. At the theoretical part we present and typify translation shifts. These shifts were introduced by J. C. Catford (1965). We, beside to review his limited classification of these shift, typify them in more details based on the structures which they are made.

Another part of theoretical study is to clarify and explain the phenomenon of readability, and introduce a new method of measuring readability so that at the empirical part of research this method will be applied. 
At the other hand, in empirical section of research, more comprehensively, we are to do some practical investigations on these two variables (level of readability and translation shifts), and their relations, in respect to the cases of study in order that the typology and frequency of translation shifts in each translation be found, the text readability of each translation be measured, the effects of translation shifts on the level of readability in each case be analyzed, and, at last, some generalizations will be made, regarding the effectiveness of types of shifts on readability of translations for children.

\section{Theoretical Part}

\subsection{Extension of Typology of Translation Shifts}

The term of Translation shifts is used for the first time by Catford himself (1965). He introduces it in his book entitled 'Linguistic Theory of Translation'. Based him, shifts are "departures from formal correspondence in the process of going from SL to TL" (Catford, 1965:73). Shifts cause new encoding of the ST in the TT. These shifts are due to the structural and lexical differences between SL and TL. He divides them into two major kinds: 1. Level shifts, 2. Category shifts.

1-Level shift (L shift): "A SL item at the linguistic level has a TL translation at a different level" (ibid).Catford, following hollidayan grammar, accepts four linguistic levels of phonology, graphology, grammar, and lexis. According to him translation is impossible between the levels of phonology and graphology or between either of these levels and the levels of grammar and lexis, since they are lack of relationship to the same substance as the necessary condition of translation equivalence (ibid). Therefore translation shift is possible only from grammar to lexis and vice versa.

In translating from English to Persian, when encountering, introductory or mid phrase, we should note that this structure is a marked expression in English (starting with pp), but Persian lacks it. So translator has to render this structure (grammar level) into explicit clause (lexis level) in Persian to reveal the implied meaning of the phrase. For example:

E: Half blinded with tears, he went home.

$$
\text { Pند : او در حالى كه از اشك نيمه كور شده بود، به خانه بركثت. P }
$$

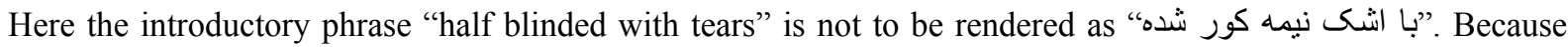
such a structure in Persian can't convey the component of "while" and subject "he" which are implied in the English structure. Therefore the translator has to make them explicit and translate the phrase as an explicit clause ”او در حالى كه از اشك نيمه كور شده بود،،"

Therefore level shift has only one shift type of "L", translating from English to Persian. That is, rendering ST introductory or mid phrase (since some times the phrase comes in the middle of the sentence) to an explicit clause in TT.

2-Category shift: It is a general term to refer to the change of any category (structure, class, unit, and system) in the process of going from SL to TL. This kind of shift is subdivided into four sub kinds as follows:

a. Structure shift: this shift is amongst the most frequent category shifts in translation. Through this shift the structure of ST is changed into the structure of TT (ibid: 77). This may leads to changing the word order, turning the active/positive sentence to passive/negative sentence respectively

In translating from English to Persian this kind is very common. This may lead to rendering active sentence to passive or vice versa, or changing parts of speech of the ST structure element in the TT. This kind is subdivided into the following types:

- $\quad$ Rendering a passive sentence of ST as an active one in TT is very common, when going from English to Persian. We call this type Structure active shift $\left(\mathbf{S}_{\mathbf{a}} \mathbf{s h i f t}\right)$.

- $\quad$ The inverse change of structure active shift is structure passive shift $\left(\mathbf{S}_{\mathbf{p}} \mathbf{s h i f t}\right)$, in which the active voice of ST sentence is made passive in the TT. Generally in translation from English to Persian this type of shift is much less occurred.

- The next structure shift is titled Structure class shift $\left(\boldsymbol{S}_{\mathbf{c}}\right.$ shift), where some parts of speech (classes) of the ST will be deleted or replaced in the TT.

b. Class shift: Catford, regarding Halliday, defines a class as "that grouping of members of a given unit which is defined by operation in the structure of the unit next above" (ibid: 78). Plenty of shifts of class (e.g. noun, verb, adjective, and adverb) could be detected in translating from English to Persian: 
- The verb of ST is changed to its Persian equivalence noun. We call this type Class noun shift $\left(\mathbf{C}_{\mathbf{n}}\right.$ shift). The inverse operation (noun to verb) is named is Class verb shift $\left(\boldsymbol{C}_{\boldsymbol{v}}\right.$ shift).

- The English verb or noun is changed to adjective in Persian translation. This sort is named Class adjective shift ( $\boldsymbol{C}_{a d j}$ shift).

- There may be other type of class shift in which adjective changed to adverb as well, which named class adverb shift $\left(\mathbf{C}_{\mathbf{a d v}} \mathbf{s h i f t}\right)$. This special type of shift is lees made than three previous types.

c. Unit shift: This refers to the change of a rank (word, group, clause, and sentence) - that is departure from formal correspondence in which the translation equivalent of a unit at one rank in the SL is a unit at a different rank in the TL (ibid: 79).

- Through translation a group in ST may turn to a clause in TT is Unit clause shift ( $\left.\boldsymbol{U}_{c} \mathbf{s h i f t}\right)$ producing clause unit.

- Or a ST word of is rendered as a group in TT, is Unit group shift $\left(\boldsymbol{U}_{g} \mathbf{s h i f t}\right)$ producing group unit.

- Yet there is two another types. One of them is Unit word shift $\left(\boldsymbol{U}_{w} \mathbf{s h i f t}\right)$, which is made when a ST group or clause or a sentence is rendered as a word in TT.

- And Unit sentence shift $\left(\mathbf{U}_{\mathbf{s}} \mathbf{s h i f t}\right)$ the latter is produced when a word, group or clause of ST is turned to sentence in the TT.

d. Intra- system shift: we use the term for those cases where the shifts occurs internally, within a system. That is, for those cases where SL and TL possess systems which approximately correspond formally as to their constitutions. But translating from SL to TL involves selection of a non-corresponding item in the TL system (ibid: 80).

In translating from English to Persian the systems of number, deictic, verb tense, and person are correspondent formally in two languages, But in translation these correspondences are not essentially observed:

- The indefinite determiner "a" is rendered as definite determiner "iآن" in Persian. Although there is correspondent term of "a" in Persian (《ی)/(ي) which is indefinite. We name this sort Intra-system definite $\operatorname{shift}\left(\boldsymbol{I}_{\text {def }}\right.$ shift $)$.

- While if change occurred in opposite direction (definite to indefinite determiner) we have Intra-system indefinite shift $\left(\boldsymbol{I}_{\text {indef }}\right.$ shift $)$

- The next type is related to the number system in English and Persian. Here, as well, there is a formal correspondence between two language systems; translation of these two systems has some departures from formal correspondence. In Persian, unlike to English, inanimate nouns are often determined structurally singular. So translator, knowing this matter, adheres to the common used expression and turns ST plural noun into singular form in TT. This type of Intra-system shift is called Intra-system plural shift $\left(\boldsymbol{I}_{p 1}\right.$ shift $)$.

- While if change occurred in opposite direction (plural to singular) we have Intra-system singular shift (Is shift).

- Another type of intra-system shifts which we could realize in translating from English to Persian is intra-system person shift $\left(\mathbf{I}_{\mathbf{p}}\right.$ shift $)$ in which the persons used in ST and TT are not the same. The person of English text, for example, is the plural first person (we), while that of Persian text is the plural third person (they), even though, totally, English and Persian languages have correspondent systems of person.

And intra-system tense shift ( $\left.\mathbf{I}_{\mathbf{t}} \mathbf{s h i f t}\right)$, like other cases, shows a departure from the correspondence existed between languages' systems of English and Persian. This time, it refers to the tense systems of the two languages. For example, the time tense of ST is simple past, while that of the TT is simple present. Even though the translator could use simple past tense in TT as well, he did not. Thus such a shift comes to exist. Here noticing to an important point is vital. That is there are some tenses in the systems of two languages which are not completely correspondent to each other. In fact these items are not the concern of this study because they are not found in our cases of study.

After typifying the translation shifts, another important classification should be made regarding to them. It is done based on the complexity and simplicity of them. One shift is complex if its structure includes more than one word. And one shift is simple when its structure is comprised of only one word. Now we could classify all the introduced shifts in a binary way as simple vs. complex shifts as follows: 
Table 1. Types of shifts

\begin{tabular}{ccc}
\hline Shift Name & Abbreviated as & Simple/ Complex \\
\hline Class adjective shift & $\mathrm{C}_{\mathrm{adj}}$ & simple \\
Class adverb shift & $\mathrm{C}_{\mathrm{adv}}$ & simple \\
Class noun shift & $\mathrm{C}_{\mathrm{n}}$ & simple \\
Class verb shift & $\mathrm{C}_{\mathrm{v}}$ & simple \\
Intra system definite shift & $\mathrm{I}_{\text {def }}$ & simple \\
Intra-system indefinite shift & $\mathrm{I}_{\text {indef }}$ & simple \\
Intra-system person shift & $\mathrm{I}_{\mathrm{p}}$ & simple \\
Intra-system plural shift & $\mathrm{I}_{\mathrm{pl}}$ & simple \\
Intra-system singular shift & $\mathrm{I}_{\mathrm{s}}$ & simple \\
Intra-system tense shift & $\mathrm{I}_{\mathrm{t}}$ & simple \\
Level shift & $\mathrm{L}_{\mathrm{a}}$ & complex \\
Structure active shift & $\mathrm{S}_{\mathrm{a}}$ & complex \\
Structure passive shift & $\mathrm{S}_{\mathrm{p}}$ & complex \\
Structure class shift & $\mathrm{S}_{\mathrm{c}}$ & complex \\
Unit clause shift & $\mathrm{U}_{\mathrm{c}}$ & complex \\
Unit group shift & $\mathrm{U}_{\mathrm{g}}$ & complex \\
Unit sentence shift & $\mathrm{U}_{\mathrm{s}}$ & complex \\
Unit word shift & $\mathrm{U}_{\mathrm{w}}$ & simple \\
\hline
\end{tabular}

As could be seen, from the above mentioned shifts $\mathrm{L}, \mathrm{S}_{\mathrm{a}}, \mathrm{S}_{\mathrm{c}}, \mathrm{S}_{\mathrm{p}}, \mathrm{U}_{\mathrm{c}}, \mathrm{U}_{\mathrm{g}}, \mathrm{U}_{\mathrm{s}}$ are complex, and the rest are simple. This means that a large part of shift operations are done on single words of any kind. For example look at class shifts as a whole. They are changing the parts of speech of the intended words of ST in TT. Or, look at intra-system shifts. Totally the operate on words- $I_{\text {def }}, I_{\text {indef }}$ on determiners $, I_{s}, I_{p l}$ on nouns and pronouns, $I_{p}$ on verbs and pronouns, $\mathrm{I}_{\mathrm{t}}$ on verbs.

It should be mentioned that not every verb structure affected by $\mathrm{I}_{\mathrm{t}}$ is verb word. Very few of them are phrases (groups) as well. For example the tense of ST verb (had never seen) is changed from past perfect to present perfect in the TT verb (نديده است). Verb groups, in such cases act as a unified (inseparable) group either produced or changed by $\mathrm{I}_{\mathrm{t}}$. Thus in this case verb groups, accepted as exception, their shift operations are classify as simple.

$\mathrm{S}_{\mathrm{a}}$ and $\mathrm{S}_{\mathrm{p}}$ are of complex shifts, although they are mainly operating on the verbs of the sentence. Two important reasons existed for this classification: 1-neary all of the verbs acted by these shifts are at unit group, 2- these shifts in fact change the voice of the sentence addressed totally. Thus $S_{a}$ and $S_{p}$, unlike $I_{t}$, are considered as complex shifts. $\mathrm{S}_{\mathrm{c}}$ is done on group and above it. Thus all types of structure shift are of complex shifts.

Up to now, all types of a certain translation shift were pertaining totally to either simple group (class shifts, and intra-system shifts) or complex group (structure shifts). But it is not true for unit shifts. They all, except $U_{w}$, are complex shifts. Since, they are done on the group, clause and sentence units.

Level shift as the last type is a complex shift. As mentioned before, it produces clauses in TT from introductory phrases of ST.

What is said up to now about translation shift typology and classification will be inserted in our cases' examinations in the practical part of the research. That is, we are to contrast three translations of Alice with original text word by word, line by line to reveal all the typology and frequency of shifts in each of them in detail. Before that we should introduce another important theoretical part of our study, which is readability and its measurement.

\subsection{What Is Readability and How It Should Be Measured?}

Ghoreishi accounts two kinds of factors affecting the level of readability of a text: linguistic and nonlinguistic ones (Ghoreishi, 1995: 158). The former includes word length (syllables number) and sentence length (words number), and the later is related to the text size, illustration, punctuation, tables (ibid).

DuBay in his book 'The principles of readability' has a different view about readability. He believes that 
readability should not be confused with legibility (which concerns to typeface and layout) (DuBay, 2004: 3). Gorge Klare (1963) defines readability as "the ease of understanding or comprehension due to the style of writing" this definition focuses on writing style (ibid). Another definition is stated by Gretchen Hargis and her colleagues (1998) as "the ease of reading words and sentences" (ibid).

Venuti (2000) argues that readability is a common feature of domesticated translation in order for the readers (here children) could perceive and comprehend the text in their own language (Venuti, 2000: 341). So in the process of translating, the textual features selected and organized should not be strange and vague for the children readers.

According to Tina M. Lowrey two major contributors affecting the level of readability are vocabulary and syntax. The specific words selected and how the words are strung together into sentences can both impact message complexities (2008:5-6).

First, the words selected may be short and simple, single-syllable words that first-graders can easily understand. Conversely, the words may be multi-syllabic obscure terms that only college graduates with a sophisticated vocabulary are familiar with. Second, the way in which these words are strung together into sentences (known as syntax) can be as simple as possible (e.g., one clause written in the active voice with no negation) or can be quite complex (e.g. several clauses written in the passive voice with negation). These two factors are often combined when assessing the reading level of a passage of text (ibid).

One of the most usual way of measuring readability of a text is the application of formula. One of the most appropriate formulas for measuring readability of students (unassisted) readings is Gunning formula (Fog index) (ibid: 56-57). According to DuBay, Fog index counts the number of words and the number of sentences to calculate average sentence length (based on the assumption that longer sentences are more difficult to process). In addition, words with three or more syllables are counted to assess word difficulty. Thus, Fog index uses two variables: 1- average sentence length (ASL) and 2- the number of hard words, for each 100 words. Applying these two variables, his formula determines the grade level of the readers to whom the calculated text is to be appropriate (2004: 24).

$$
\text { Grade level }=.4 \text { (average sentence length }+ \text { hard words) }
$$

Where

$$
\text { Hard words }=\text { number of words of more than two syllables. }
$$

A relatively new approach to study the text readability is that of cognitive linguistics. Cognitive linguistics, at the beginning 1970s, promoted the idea that reading was largely an act of thinking. It is organization and coherence of the text, which are structural factors addressed by cognitive linguistics. According to Knuth and Jones (1991),based on cognitive linguists, the factors including predication, types of narration, types of sentences, phrases, and clauses, nominalization, active and passive voices, embeddings are accounted as factors affecting way from which the readers interpret the meaning of the text( cited in DuBay, 2004: 32). Among the ideas they promoted by cognitive linguistics were:

1. Meaning is not in the words on the page. The reader constructs meaning by making inferences and interpretations.

2. Information is stored in long- term memory in organized "knowledge structures". The essence of learning is linking new information to prior knowledge about the topic, text structure or genre, and strategies for learning.

3. A reader constructs meaning using Meta cognition, the ability to think about the learning process and control it (i.e. to plan, monitor comprehension, and revise the use of strategies and comprehension, attribution, and beliefs about the relationship among performance, effort, and responsibility) (ibid).

Among the scholars studied in this field is Walter Kinsch (1977). For measuring the text readability, he proposed to measure the number of prepositions in a text. A preposition consists of a predicate and one or more arguments. An argument can be a concept of another argument. A concept is the abstract idea conveyed by a word or phrase. According to DuBay:

"Kintsch at first was quite critical of readability formulas. He said they are not based on modern linguistic theory and they over look the interaction between the reader and the text. Over four years, however, he and his associates revised this position. He eventually admitted that these formulas are correlated with the conceptual properties of text, and that vocabulary and sentences lengths are the strongest predictors of difficulty" (Kintsch \& Miller, 1981: 222. cited in Dubay, 2004: 33).

In another place he states: 
"Critics of the readability formulas (e.g. Manzo 1960, Bruce et al 1981; Selzer 1981; Redish and Selzer 1985; etc) rightly claim that the formulas use only surface features of text and ignore other features like content and organization. The researches show, however, that these surface features- the readability variables- with their limitation have remained the best predictors of text readability. (ibid: 35).

At the other hand, Chesterman believes that in order to measure readability one could utilize questionnaires, interviews, or 'specially' constructed tests (2002: 90-91). He motioned to Puurtinen (1994), who we referred in chapter two and explained his work. Yes, what we are looking for is testing.

In 1953, Wilson Taylor created the cloze test to estimate the difficulty of a text by measuring an individual understanding of a given text. In this test, the intended audience is given a text with missing words at regular intervals (usually every fifth word) and then he/she is asked to fill in the blanks. The percentage of correct words is calculated to produce the cloze score. If the reader fills in the blanks correctly, this indicates that he/she understands the text. That is, the higher the score, the less difficult the text, (Hend S. Al-Khalifa and Amani A. Al-Ajlan, 2010: 107). The cloze scores can categorize the reading into three reading levels: independent reading level, instructional reading level, and frustrational reading level, and thus the text realized as easy, normal, or difficult respectively (ibid).

Table 2. Reading level

\begin{tabular}{cc}
\hline Independent reading level & (material is too easy) $60 \%$ and above \\
\hline Instructional reading level & (material is normal) $40-60 \%$ \\
\hline Frustrational reading level & (material is too difficult) under $40 \%$ \\
\hline
\end{tabular}

Considering all these claims on measuring readability, we in this study embark on innovations in this field. So in order to validate of our measurements, we use testing (cloze test) in addition to readability formula of Fog index.

We use Fog index in order to get a relative insight about the level of the readability of these cases, and determine the appropriate students of certain grades to answer the cloze tests. At the other hand we use cloze tests to cover such aspects of text as types of sentences, phrases, and clauses, nominalization, active and passive voices, embeddings, etc which influencing the readability of text. Otherwise, applying one of them merely will not lead us to such considerations.

At the other hand, if we are to determine the difficulty of a text we should consider both readability of the text and reading ability of the reader in order. But, as mentioned in chapter one, in this study we modulate our aims and turn the focus from text difficulty to sheer text readability. Thus to study sociologically and psychologically on readership of TChL is not pertain to our study.

Thus we present to the children the samples of the three translations in form of cloze tests, where the missing words or groups or even clauses are all those shifts found in those samples. And in order to neutralize the effects of different reading ability factors (like age, gender, motivation of readership), we select randomly the reader subjects. Otherwise we are entailed to determine the effects of these changing reading ability variables on the validity of our findings as well, which is not the object of our study.

One exception to this axiom is the level of education of the intended reader subjects. That is we applied fog index formula to determine the appropriate school grade of students to read the texts. Otherwise we have to cover all of the school grades of students even randomly. Consequently it will make the results uncertain. Thus we insert, and state that, in our explanation to our study that this field work is to be done on the subjects of the same grade of education.

\section{Practical Part}

In this part the theoretical matters of the study will be the base for conduction of empirical study. This part is very comprehensive, and at the same time quantitative. Thus it necessitates stage by stage performance in order to collect data.

Introducing The Case Studies ('Alice's Adventures in the Wonderland' and its three Persian translations): The story of "Alice's Adventures in the Wonderlands" is the most outstanding work of Lewis Carrol. It was written in Victorian Period. In that time it was looked unusual, since it has no conformation with the governing morality and didacticism to children. This work by no way interests in children education. But it is a funny story to entertain the children. The main reason of selecting this work for our study is its popularity between children. 
The second reason is the existence of plenty translations of it into Persian. More than 11 translations of it were produced from 1959 to 2002.In this study we select three translations which are considered as better than others.

Selecting Some Excerpts of the ST and its three Persian TTs, and comparing the Persian excerpts with their English source text to reveal the translation shifts in them: Here we select and present some extracts of the original text with their Persian equivalents from three introduced translations. We are to choice some portions more or less of the same word number from the beginning, middle, and ending of the ST. Thus we cut 460 words from the chapter one (DOWN THE RABBIT-HOLE), 457 words from chapter eight (THE QUEENS CROQUET-GROUND), and 456 words from chapter eleven (WHO STOLE THE TARTS?). Then the equivalences of these excerpts are cut from three translations A, B, and C.

Determining the Appropriate School Grade of the intended subject readers by means of fog index formula: In order to gain the appropriate grade level of each translation case, we should determine the grades of three excerpts of each case via the implementation of the fog index, and then get the average of them. Based on this formula, we ought to present the cloze tests to the $7_{\text {th }}$ grade students, to gain appropriate and useful data about the level of readability of each cases of study.

Constructing Cloze Tests of these excerpts and presenting them to the target subject readers: In this part we prepare and present the cloze tests to the students. Regarding it, two important points should be made and noticed. The first one is about how to prepare the tests, and the second one is about how to select and sample the readers. We consider and explain these two points one by one.

We use fog index in order to get a relative insight about the level of the readability of these cases, and determine the appropriate students group of certain grade to answer the cloze tests. At the other hand we use cloze tests to get an affirmative level of readability of the texts (by covering such textual factors as types of sentences, phrases, and clauses, nominalization, active and passive voices, embeddings, etc).

Thus we present to the children the samples of the three translations in form of cloze tests, where the missing words, groups, and clauses are all those shifts found in those samples.

To conform our tests to the intended purpose of study, we are to modulate the traditional frame work of cloze test. As mentioned above, in traditional cloze tests, the missing words should be at regular intervals (usually every fifth word). But since in our study we present the shifts as the blanks, thus such a regular intervals may not be retained.

As well, the number and kind of missing words, groups, and clause in three test cases may not be the same. In fact, this feature makes one kind of test easier or harder than the two other kinds of tests.

Our population of study is all the of $7^{\text {th }}$ grade students of Birjand schools, which is about 3752 students. In order to measure the sample size of subjects of the study, we apply the Cochran's (1963, p 75) sample size formula:

$$
\mathrm{n}=\frac{\mathrm{N} * \mathrm{Z}^{2} * \mathrm{p}(1-\mathrm{p})}{\mathrm{e}^{2}(\mathrm{~N}-1)+\mathrm{Z}^{2} * \mathrm{p}(1-\mathrm{p})}
$$

Thus, the sample size of the study is 186 students of $7_{\text {th }}$ grade of Birjand students. We select randomly from all the male and female students throughout all of the schools. We give to each student one test case (for example close test A, or B, or C). Therefore we ought to divide equally this sample size to the three test types. So for each type we collect 62 tests answered by the subjects.

At the next chapter we present and analyze in details the findings of our study by computational and analytical programs of SPSS and EXCEL. And show the findings by tables and charts. And answer the questions of the study. Then we could prove or disapprove our hypotheses.

\section{Analyses of the Results}

\subsection{Answering the Questions and (In) Stabilizing the Hypotheses of the Study}

\section{1- What differences do the three Persian translations (of Alice) have, regarding to their translation shifts?}

In order to determine the differences of theses translations by their shifts, the typology and frequency of shifts existed in each of them should be measured statistically. Thus, in order to do that the excerpts of each translation should be compared with their ST excerpts.

What is absolutely clear is this fact that these translations are different from each other, regarding their shift typology and frequency. Two show these differences clearly, the frequencies of shifts in each translation are demonstrated in chart, as follows: 


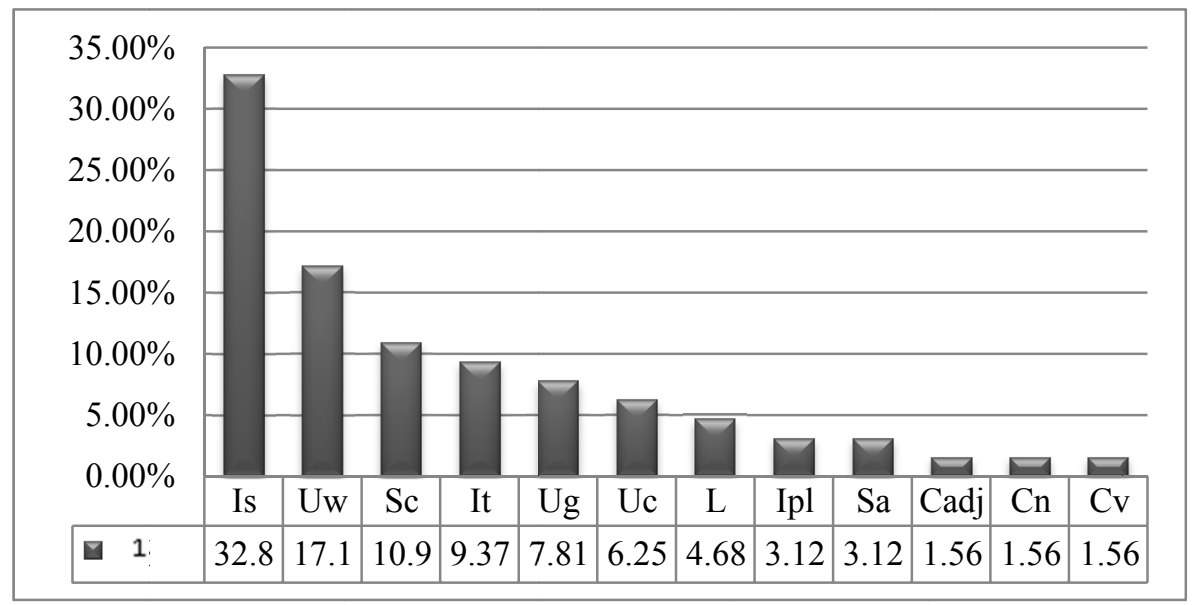

Figure 1. Shift Frequency- A

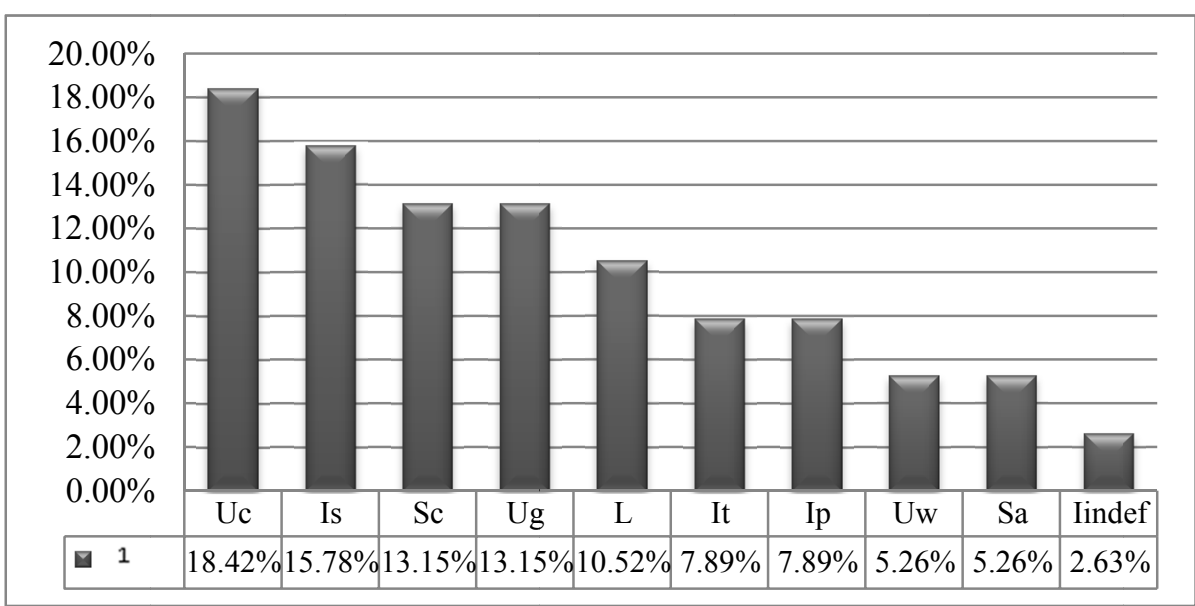

Figure 2. Shift Frequency- B

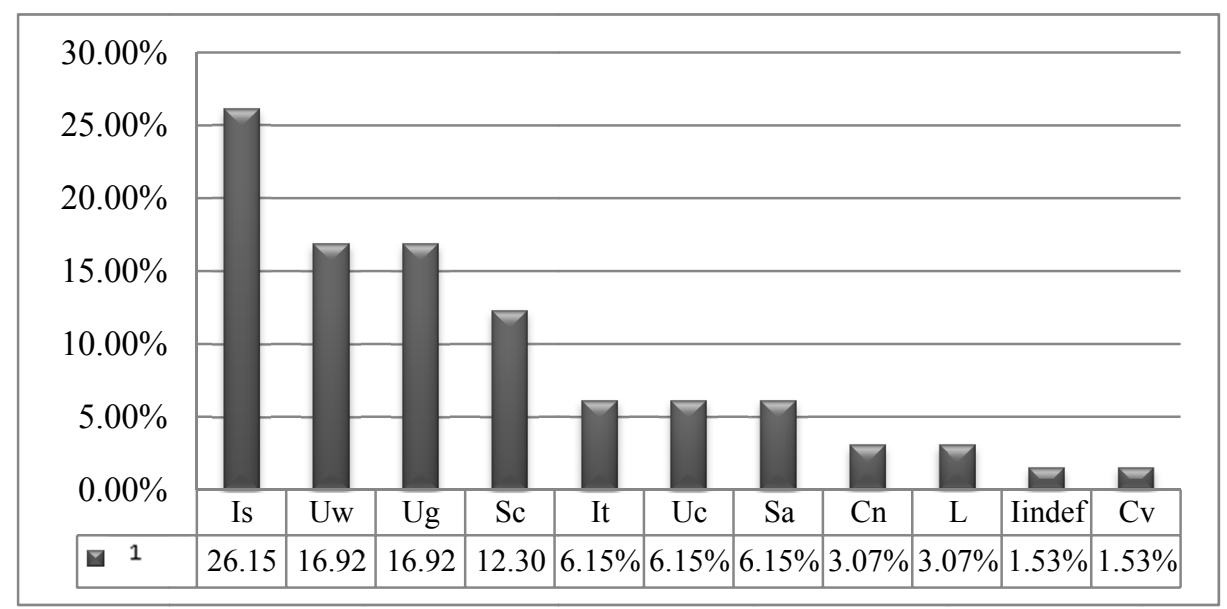

Figure 3. Shift Frequency- C

These diagrams show that three translations differ from each other by the frequency and typology of translation shifts in them. Thus, each translator used different structures and lexis in his translation. The types of simple shifts in translation A is high, that is 7 of 12.In translation B it is 5 of 10, and in translation $\mathrm{C} 6$ of 11. At the same time, the rate of repetition of these simple shifts in A is more than B and C.As could be seen in the chart A, about $70 \%$ percent of all existed shifts in A is simple. This rate in B is $39 \%$, and in $\mathrm{C}$ is $58 \%$. 
Thus hypothesis 1: Three Persian translations of Alice are different from each other by typology and frequency of shifts existed in each one is right. We after comparing the excerpts of three translations with their STs and analyzing the data, find that typology and frequency of shifts in these translations are different.

\section{2- The level of readability of what translation is high and what is low? Prioritize them.}

the reason to prefer cloze test rather some other tests like multiple choices, or open ended questions id that in this study the authors are seeking to prove this affair that the readability of a text depends on the lexis and structures implemented in it. Thus focusing on these aspects of text and presenting them as missing lexis and structures let to reveal how the readers deal with them. Otherwise, in other forms of tests such an observation cannot be made.

After making exam, the test results of all 62 tests of each case (A, B, C) inserted in analytical program of SPSS. And the average score -the percentage of correct answers- of each test case (A, B, C) were measured. The three close tests were answered as follows:

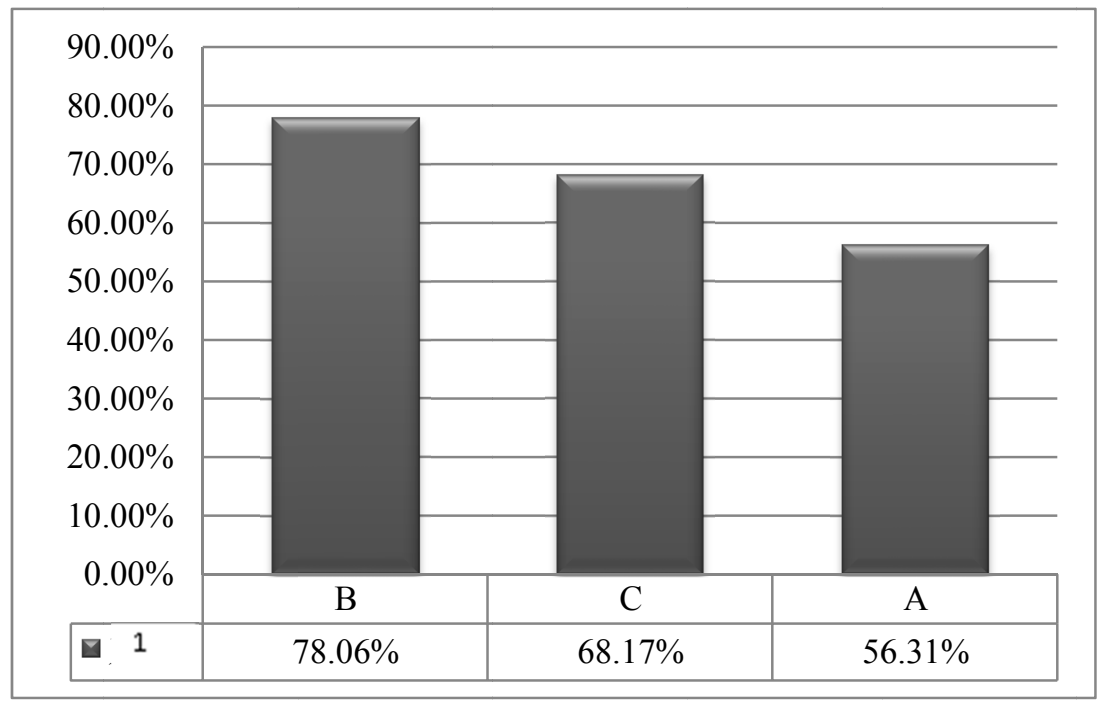

Figure 4. Total Readability of Cases

Therefore translation B is the most readable one. The next one is translation B, and the least readable one is translation A. So the level of readability of these translations is different from each other due to the different structures and lexis (translation shifts) implemented in each of them.

These three versions have the same original ST, but their levels of readability differ from each other. And this was shown by focusing on their structural and lexical differences which presented as the blanks in the cloze tests. And, naturally, the extent of answering correctly to cloze test is depend on the extent of choosing correctly the appropriate structure and lexis for the blanks. The more the questions answered correctly, the higher score the test will get.

Thus Hypothesis2: The level of readability of these translations tends to be different from each other due to the structures and lexis contained in them is true. By determining the target readers, constructing the cloze tests from the selected excerpts of three translations, and presenting them to the children to answer, the following ranking of readability was obtained: 1) B, 2)C, 3)A.

\section{3- How the shifts occurred in each translation does affect the level of readability of that translation?}

In order to reveal the relationship between readability and the shifts of each translation, the answering to cloze tests of each case should be scrutinized in details. As mentioned before, cloze test ,beside to determining the level of readability of text as a whole, let to measure the level of readability and understandability of the missing shifts (active and passive sentences, clauses, groups, words, nominalizations, embeddings, etc), and determine each translation shift's impact on the total readability of the translation.

Therefore, in cloze test, the readability of translation as a whole is the outcome of the accumulation of the readability of separate translation shifts of that translation. In other words, correctly choosing a translation shift in cloze test has direct relation with the level of readability of the translation. Thus we have: 


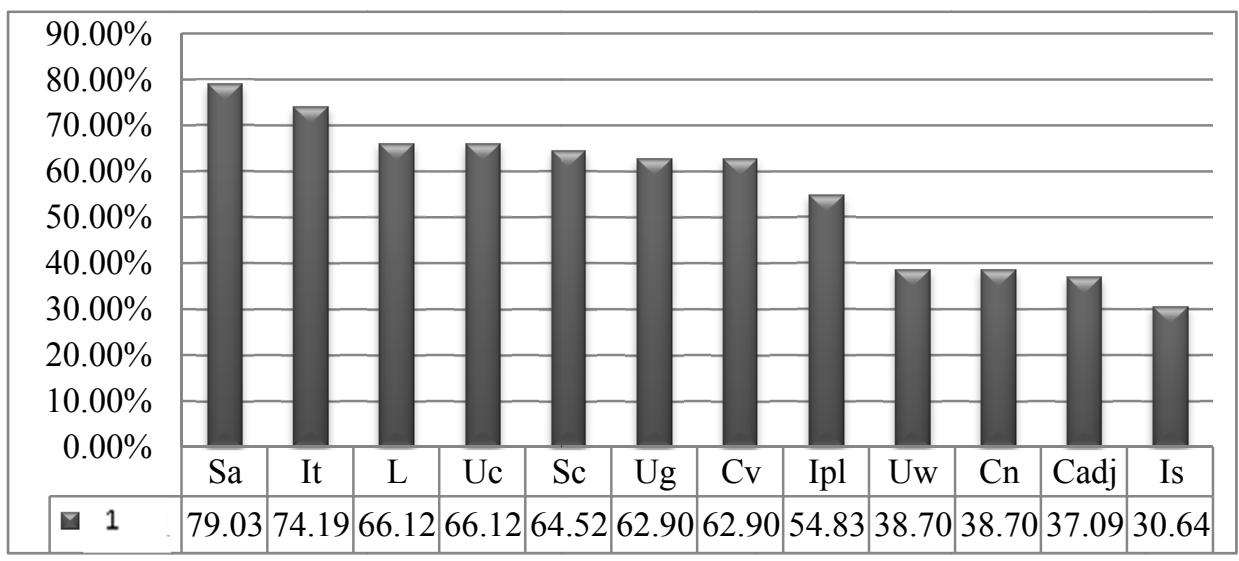

Figure 5. Shifts Effectiveness- A

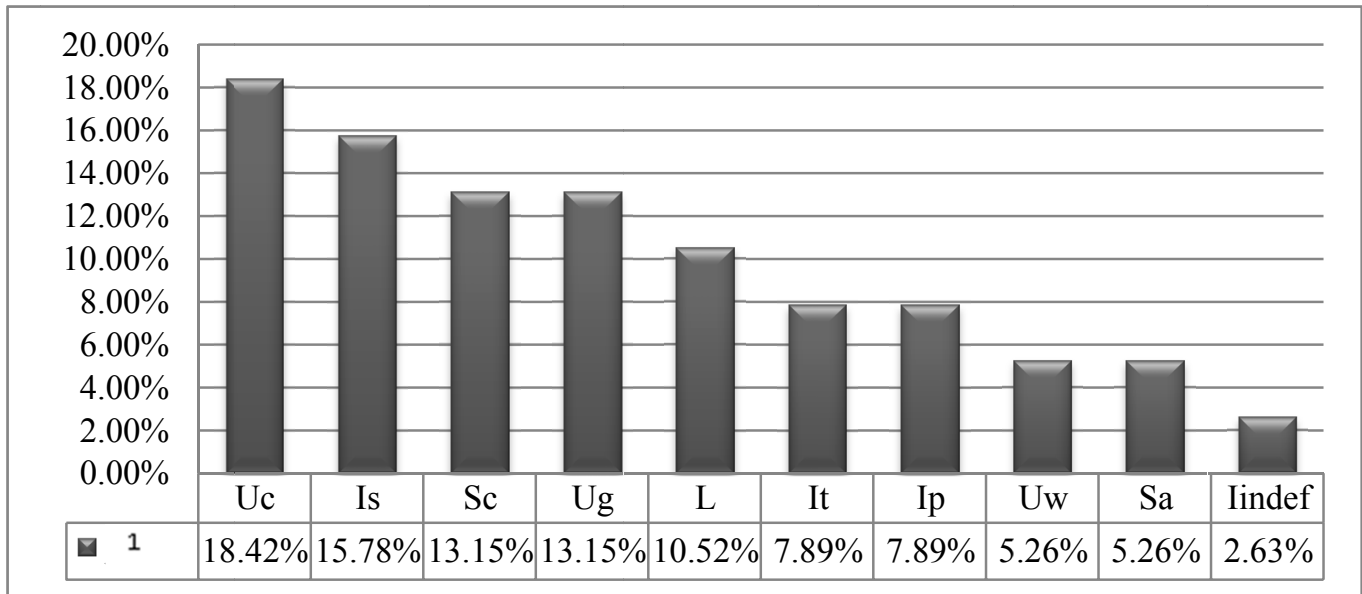

Figure 6. Shifts Effectiveness- B

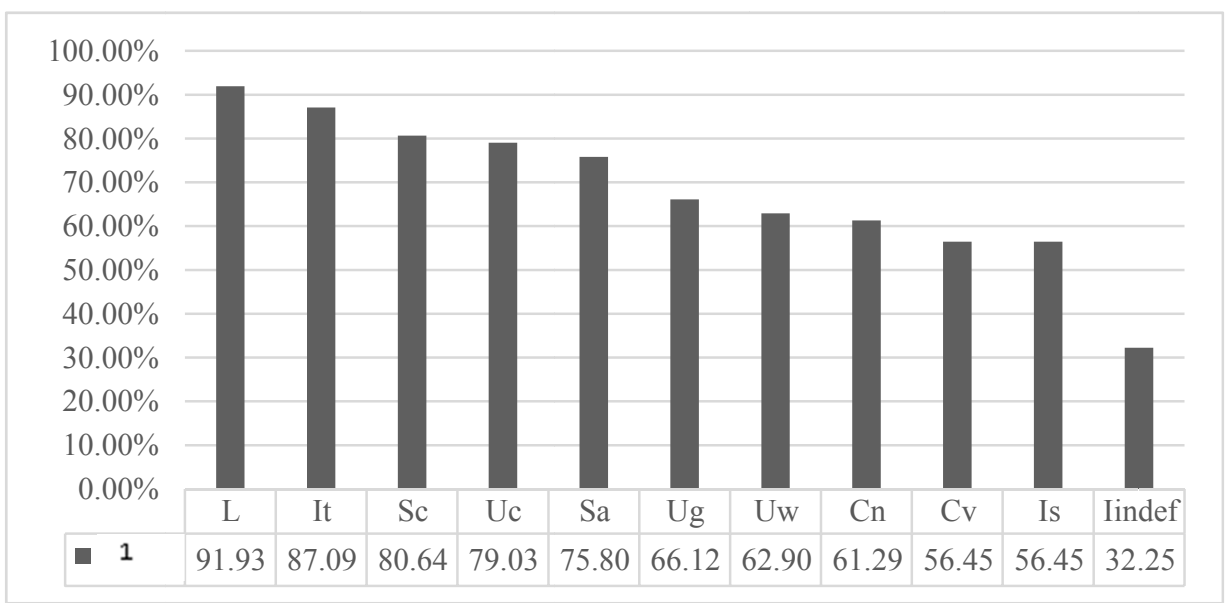

Figure 7. Shifts Effectiveness- C

Certainly the way these translations are read is different from each other. In fact, the strategies translators used make such a difference. These diagrams indicate this clearly. In translation A active verbs are the most recognizable structures for the readers, and singular nouns and pronouns are least ones. These extremes in case B is between active verbs and indefinite determiners. In translation $\mathrm{C}$, this is between clause structures and indefinite determiners. What is obvious is that active verb is very effective and indefinite determiner is very less effective by nearly all of the readers. 
Between these extremes, as explained above, different percents of effectiveness were allocated to translation shifts of each case. That is, translation shift of the same type were answered differently in three test cases. Or there are some shifts which existed only in one or two translations. Certainly these differences (in responses and in existence) make a test kind more difficult (or easier) than others.

In translation $\mathrm{A}$, the total percents of correct answers to simple and complex shifts are $48 \%$ and $67 \%$ respectively. In case $\mathrm{B}$ these are $74 \%$ and $81 \%$, while in case $\mathrm{C} 59 \%$ and $78 \%$. What is common between all three translations is this fact that complex shifts are more effective than simple shifts, although the rate of this effectiveness is different in three translations. In translation A since the occurrence of simple shifts is frequently more than that of complex ones $(70 \%$ vs. 30\%), thus reading it becomes difficult for the readers. At the other hand, in translation B the occurrence of simple shift is much less than that of complex ones (39\% vs.61\%). So it is more readable for the readers.

Of course, we could not summarize the reason of effectiveness of translation shifts only in two extremes of simple vs. complex shifts. There are some other justifications and tendencies as well. For example, as mentioned above, the effectiveness of structure active shifts are considerable. While that of class noun shift or class adjective shifts is not so, although all of these shifts are classified as simple types.

Thus Hypothesis3: The level of readability of each translation is the outcome of its shifts' impact on it is true. The effect of translation shifts on readability of three translations was determined through cloze analyzing of status of answering of each translation shift in cloze tests.

To show the supremacies of some types over the others, we should consider closely the status of effectiveness of translation shifts of the same type in three translations simultaneously, and get the average of them, and compare it with the averages of effectiveness of other types. This is what we are to do to gain the aim of the research; i.e. prioritizing translation shifts based on their effectiveness on the readability in TChL.

\section{4- What type of shift is the most and what is the least efficient in making the translation readable? Prioritize them.}

In this part, beside to prioritizing the shifts based on their affects on readability of translation of ChL, such priorities should be justified in order that reach some logical and definable rules.

In this study, totally 14 shifts were introduced, which were found in three translations by different frequencies. Considering the answering of translation shifts of the same type in each case reveals some interesting trends common between readers, when encountering the tests. To show these general trends, the average of effectiveness of each translation shift is introduced in the following chart:

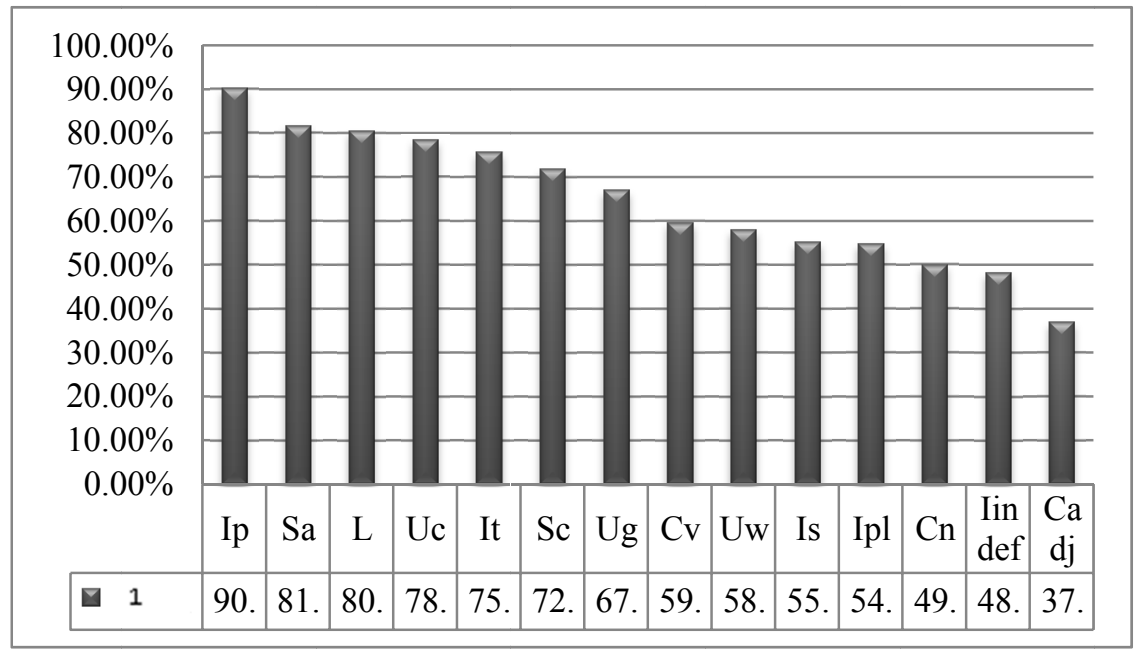

Figure 8. Shifts Effectiveness

Totally some major points could be made regarding the outcome of this prioritization:

$>$ Verb lexis- specially active verbs- are very impacting on readability of text in TChL as shown by $I_{p}, S_{a}, I_{t}, C_{v}$.

$>$ Clause structures are very effecting on readability as indicating by $L, U_{c}$. 
$>$ Group structures are effecting on readability as indicating by $\mathrm{S}_{\mathrm{c}}, \mathrm{U}_{\mathrm{g}}$.

$>$ Words - save verbs - as single units are not so affecting on readability as suggesting by $\mathrm{U}_{\mathrm{w}}$.

$>$ Nouns and pronouns either singular or plural are not effecting much as shown by $\mathrm{I}_{\mathrm{s}}, \mathrm{I}_{\mathrm{pl}}, \mathrm{C}_{\mathrm{n}}$.

> Indefinite determiners are not well recognizable for children as proposed by $\mathrm{I}_{\text {indef. }}$.

$>$ Adjectives lexis is the least effecting on the readability in TChL as claimed by $\mathrm{C}_{\text {adj. }}$.

$>$ Thus the total rate of complex shifts -i.e. $L, U_{g}, S_{c}, U_{c}, S_{a}$ - have greater affect on readability than that of simple shifts - $\mathrm{C}_{\text {adj }}, \mathrm{C}_{\mathrm{n}}, \mathrm{C}_{\mathrm{v}}, \mathrm{I}_{\mathrm{indef}}, \mathrm{I}_{\mathrm{p}}, \mathrm{I}_{\mathrm{pl}}, \mathrm{U}_{\mathrm{w}}, \mathrm{I}_{\mathrm{t}}, \mathrm{I}_{\mathrm{s}}$.

$>$ At the same time, along complex shifts, those which operating on the clause have supremacy over those working on the group structure.

And between simple shifts those are connecting to verbs are more effective than those pertaining to nouns and adjectives.

Thus Hypothsis4: The more structurally and lexically simple a shift, the more effective it tends to be on the readability of translation is wrong. In our study the negative of this statement was approved. That is the more structurally and lexically simple a shift, the less effective it tends to be on the readability of translation, save those impacting on the verbs.

\subsection{Limitations \& Strengths of the Study}

Of course this research has some strengths and limitations as well. Of the strengths and innovations of this study is that the procedure of measuring readability taken by this study is a new one which solves many problems regarding readability measurement. For example it, in addition to grading the text for the readers, let the researcher discover the extent of effect of any part of the text on the total readability of that text. This problem was the main concern of cognitive linguistics (see methodology section). They, although believe that structure and lexis do affect on the readability, cannot invent a method to calculate this effectiveness.

Another strength of our study is to extension of Catford's shifts in concordance with our aim. Catford introduced two main kinds of shifts: Category and Level shifts. He divided the first one into four sub kinds and exemplified them. Contrasting TTs' excerpts with their STs, we recognized that these shifts could be classified into types. Thus, 18 types were introduced. Besides, we divided them into two groups of simple and complex (see 2.1.1).

Therefore the result of readability of translations is valid from this perspective that the tools of measurement are selected with regard to the addressed variables of the study. That is, determining the effect of different structures and lexis on readability. Thus grade level of the readers was measured by Fog index formula, the sample size of the subject readers was measured by Cochran formula, and cloze tests were constructed to cover those intended structures and lexis in the measurement of readability. Therefore the differences of structures and lexis used by in three translations lead to their difference in the level of readability.

About the limitations of this study we could state that the excerpts of the translations were cut from the prose parts of the text merely. In fact we intentionally ignored the verse parts of the text. We did that for some reasons:

- As these excerpts are then analyzed by readability formula to determine the grade level of the subject readers, including verses make this calculation impossible.

- This excerpts at the practical stage should be constructed as cloze tests, thus if verses were implemented in them, consequently answering the blanks of the verses could be very hard for student.

- Generally this research tends to study on readability of prose, not verse.

Another limitation is this reality that Catford's shifts could not include all of the transformations occurred in the process of going from ST to TT. Nonetheless, ignoring some major shifts not included in Catford's, we do our study under the title parenthesized term of (Based on Catford's Theory of Equivalence).

The last limitation which we could find is that, although we introduced 18 types of shifts in chapter three, only 14 of 18 have been found in the excerpts. Shifts of $\mathrm{C}_{\mathrm{adv}}, \mathrm{I}_{\mathrm{def}}, \mathrm{S}_{\mathrm{p}}, \mathrm{U}_{\mathrm{s}}$ have not been studied in this research.

The justification which we could bring in defending this study against this limitation is that we, in fact, conduct our study on the three translations of "Alice's Adventures in the Wonderlands". As measured in part 4.1 the frequency of these four shifts became 0 in three translations. That is even one case of these of these shifts have never been found in translation excerpts. Thus we have to ignore them in our constructed cloze tests, and in considering their effects on readability.

As the last statement of this chapter, we recommend further extended studies on this topic, so that through them 
the cited limitations of this research will be removed. Thus new area of the issue of readability in TChL will be discovered.

\section{Conclusion}

The present study addressed the issue of readability in TChL. We conduct this study by applying theory of translation shifts of Catford on three Persian translations of "Alice's Adventures in the Wonderland". We tended to extend the knowledge of how to translate $\mathrm{ChL}$ in a way that the criteria of readability could be preserved and enhanced through taking appropriate strategies of translation.

Different process and methodology were taken for answering the questions of the study. The first question was to determining the differences of three translations with regard to their translation shifts. To do that, first, some excerpts of the same place were cut from each translation. Then, they were compared with their STs to reveal the translation shifts in them. Consequently, the obtained data were analyzed and demonstrated by tables and charts. What gained was this fact that these translations differ from each other by typology and frequency of their translation shifts. Thus the descriptive hypothesis stating there is such difference between the translations was proved.

The second question was to measure the readability of these three translations. To measure the level of readability we invent a two-stage procedure. Through this procedure, first, the level grade of target readers was calculated by Fog index formula. Then some cloze tests were constructed from the selected excerpts of each translation, in which the blanks were those found shifts. We applied cloze tests to cover those different structures and lexis existed in those translations. By the way, we could from one hand measure the level of readability of each translation, and determine the effect of each translation shift on the readability of its translation. This second determination, in fact is the answer of third question which asked to determine the effectiveness of each shifts in each translation.

Therefore, summarizing the answers of second and third question, we reached this reality three translations have different level of readability, i.e. 1) B, 2) C, 3) A). These differences were due to the structural and lexical differences of these translations. In fact, these differences are rooted in the different translation shifts applied by translators in the process of translations. Thus, showing by diagrams, we prove that the level of readability of each translation is the outcome of effectiveness of shifts on it.

The last question which is the general aim of this study asked to prioritize the effectiveness of different types of shifts on the readability in TChL. This phase is to generalize of findings of the study to other cases in TChL. Thus to do that, we gt average of effectiveness of shifts of the same type in three translations, and ranked them.

In conclusion, it will be fruitful to conduct further studies on the phenomena of readability in TChL, while trying to resolve the limitations of this study, and giving new insights into $\mathrm{TChL}$ as a whole.

\section{References}

(1982). Alice's Adventures in Wonderland. Translated into Persian by M, Tufan. Tehran: Neda.

(1995). Alice's Adventures in Wonderland. Translated into Persian by J, Dehmeshgi. Tehran: Janzade.

(1996). Alice's Adventures in Wonderland. Translated into Persian by R, Pirzad. Tehran: Markaz Press.

(2009). Linguistic Analysis of Translation Problems, Specially in Children's Literature (PhD Dissertation in General Linguistics). University of Tehran, Faculty of Arts and Humanities.

Al-Khalifa, H. S., \& Al-Ajlan, A. A. (2010). Automatic Readability Measurements of the Arabic Text: An Exploratory Study. The Arabian Journal for Science and Engineering, 35(2C), 103-124.

Carrol, L. (1865). Alice's Adventures in Wonderland. Oxford/New York: Oxford University Press.

Catford, J. C. (1965). A Linguistic Theory of Translation. Oxford: Oxford University Press.

Chesterman, A., \& Williams, J. (2002). The Map: A Beginner's Guide to Doing Research in Translation. Manchester: St Jerome.

Cochran, W. G. (1963). Sampling Techniques (2nd ed.). New York: John Wiley and Sons, Inc.

Dubay, W. H. (2004). The Principles of Readability. California: Costa Mesa.

Even-Zohar, I. (1990). Polysystem Studies. Poetics Today, 11(1), 9-26.

Ghoreishi, M. H. (1995). The Role of Linguistics in Authoring Encyclopedias for Children (M.A thesis in General Linguistics). University of Ferdowsi, Faculty of Arts and Humanities. 
Hargis, G. et al. (Eds.). (1998). Developing quality technical information: A handbook for writers and editors. Upper Saddle River, NJ: Prentice Hall.

Kintsch, W., \& Miller, J. R. (1981). Readability: A view from cognitive psychology. In Teaching: Research reviews. Neward, DE: International Reading Association.

Klare, G. R. (1963). The measurement of readability. Ames, Iowa: Iowa State University Press.

Knowes, M., \& Malmkjare, K. (1996). Language and Control in Children's Literature. London: Routledge.

Knuth, R. A., \& Jones, B. F. (1991). What does research say about reading. Oak Brook, IL: North Central Reading Educational Laboratory.

Lathey, G. (2006). The Translation of Children's Literature. Clevedon. Buffalo. Toronto: Multilingual Matters LTD.

Lowrey, T. (2008). The Case for a Complexity Continuum. Working Paper SERIES of UTSA College of Business, 1-28. Also could be found on business.utsa.edu/wp.

Malone, L, J. (1988). The Science of Linguistics in the Art of Translation. Albany: State University of New York Press.

O'Connell, E. (2006). Translating for Children. In L. Gillian (Ed.), The Translation of Children's Literature (pp. 15-24). Clevedon. Buffalo. Toronto: Multilingual Matters LTD.

O’Sullivan, E. (2005). Comparative Children's Literature. New York: Routledge.

Oittinen, R. (2000). Translating for Children. New York: Taylor \& Francis Group.

Puurtinen, T. (1995). Linguistic Acceptability in Translated Children's Literature. Joensuu: University of Joensuu.

Reiss, K. (1982) Zur Übersetzung von Kinder- und Jugendbüchern. Theorie und Praxis. Lebende Sprachen, 27(1), 7-13.

Shavit, Z. (1986). Poetics of Children's Literature. Athens: University of Georgia Press.

Tajvidi, Kh, R. (2005). Text Leveling, Text Difficulty, and Translation: A way to Select Texts to Translate. Translation Studies, 12, 29-47.

Taylor, W. (1953). Cloze procedure: A new tool for measuring readability. Journalism Quarterly, 30, 415-433.

Toury, G. (1995). Descriptive Translation Studies - and Beyond. Amsterdam/ Philadelphia: John Benjamins.

Venuti, L. et al. (2000). The Translation Studies Reader. London/New York: Routledge.

\section{Copyrights}

Copyright for this article is retained by the author(s), with first publication rights granted to the journal.

This is an open-access article distributed under the terms and conditions of the Creative Commons Attribution license (http://creativecommons.org/licenses/by/3.0/). 